\title{
A new intertidal arthrotardigrade, Prostygarctus aculeatus gen. nov., sp. nov. (Tardigrada: Heterotardigrada) from the North of Portugal (Atlantic ocean)
}

\author{
Marcos RUBAL, ${ }^{1,2}$ Puri VEIGA, ${ }^{1,2}$ Paulo FONTOURA, ${ }^{2,3 *}$ Isabel SOUSA-PINTO ${ }^{1,2}$ \\ ${ }^{1}$ Laboratory of Coastal Biodiversity, Centre of Marine and Environmental Research CIMAR/CIIMAR, University of Porto, Rua dos \\ Bragas 289, 4050-123 Porto; ${ }^{2}$ Department of Biology, Faculty of Sciences, University of Porto. Rua Campo Alegre, 4169-007 Porto; \\ ${ }^{3}$ Eco-ethology Research Unit, Rua Jardim do Tabaco 34, 1149-041 Lisboa, Portugal \\ *Corresponding author: pfontoura@fc.up.pt
}

\begin{abstract}
A new arthrotardigrade, Prostygarctus aculeatus gen. nov., sp. nov. is described from intertidal meiobenthos samples collected at Ofir beach, Esposende, North of Portugal. The new species, an armoured arthrotardigrade of the family Stygarctidae, is easily distinguished from all the other stygarctids by an unusual caudal apparatus, which consists of a very long medial spine with two lateral furca-like processes. It is also characterised by the presence of backwardly directed dorsal spines and a pair of ventral spines. Furthermore, it has four digits on each leg, ending in simple claws. The morphological peculiarities exhibited by the new species justify the establishment of a new genus and will provide useful insights to help develop our understanding of the phylogenetic relationships of armoured arthrotardigrades.
\end{abstract}

Key words: Stygarctidae, armoured arthrotardigrades, interstitial fauna.

\section{INTRODUCTION}

There is very little literature on the marine tardigrade fauna from Portugal and there have been no extensive marine tardigrade surveys in this country. Until now, only five marine arthrotardigrade species have been recorded. Two species, Tholoarctus natans Kristensen and RenaudMornant, 1983 and Styraconyx sargassi Thulin, 1942 were recorded from the Azorean sea (Thulin, 1942; Kristensen and Renaud-Mornant, 1983; Ramazzotti and Maucci, 1983; Kristensen and Higgins, 1984b), and the other three, Batillipes similis Schulz, 1955, Echiniscoides sigismundi sigismundi (Schultze, 1865) and Echiniscoides sigismundi hispaniensis Kristensen and Hallas, 1980 from the Portuguese Atlantic coast (Centena et al., 2011; Kristensen and Neves, personal communication). Bathyechiniscus tetronyx Steiner, 1926 recorded by Marcus (1936) in the Azores was a misidentification of the very similar Styraconyx genus (Ramazzotti and Maucci, 1983; Kristensen and Higgins 1984b). Marcus' Azorean specimens (Marcus, 1936) were subsequently used by Thulin (1942) as the type material to describe Styraconyx sargassi Thulin, 1942.

During 2011, meiobenthic samples were taken from the Northern Portuguese coast. In this study specimens of an armoured arthrotardigrade belonging to a new genus and species, Prostygarctus aculeatus gen. nov., sp. nov., were found in intertidal sand samples.

The interesting arthrotardigrade described in the present study is assigned to the family Stygarctidae. Its peculiar claw morphology and distribution of cuticular spiky processes justify the establishment of a new genus, and this new data contributes to the ongoing study of the phylogenetic relationships within the armoured arthrotardigrades.

\section{METHODS}

Sediment samples for the study of intertidal meiobenthos were collected during low tide at the Ofir beach, Esposende, North of Portugal (41'31'02.71'N; $\left.08^{\circ} 47^{\prime} 14.79^{\prime \prime} \mathrm{W}\right)$, in February 2011. The Ofir beach is an Atlantic dissipative exposed beach of well sorted medium sand sediments with very low organic matter content. Meiobenthic samples were collected at the medium-tide level with a $10 \mathrm{~cm}^{2}$ core to a depth of $30 \mathrm{~cm}$. Samples were preserved in $4 \%$ neutralised formaldehyde solution with Rose Bengal for later study. At the laboratory the meiobenthos was extracted by decantation and sieved through a $40 \mu \mathrm{m}$ mesh sieve. The tardigrades were sorted and identified under dissecting microscope (Wild M5A; Wild-Heerbrugg, Gais, Switzerland). Five specimens belonging to the new species were located and transferred to microslides with coverslips. Three specimens (C-V38; C-V41; C-V42) were infused with a $10 \%$ solution of glycerine in $96 \%$ ethyl alcohol, and allowed to evaporate to glycerine over a period of several days before the coverslip was sealed with nail varnish. One of these specimens (C-V42) was pressed tightly between the coverslip and microslide in order to make critical observations of the digits and claws. Two other specimens (C-V39; $\mathrm{C}-\mathrm{V} 40)$ were permanently mounted in Hoyer's medium. 
Measurements are given in micrometers $(\mu \mathrm{m})$ and photomicrographs were made under $\times 100$ oil immersion, using a Zeiss Differential Interference Contrast (DIC) microscope equipped with digital camera and using Axiovision 4.7.1 Imaging System Software (Carl Zeiss Microimaging $\mathrm{GmbH}$, Jena, Germany). Comparisons with other species were based on their original descriptions in the literature.

\section{RESULTS}

Order Heterotardigrada Marcus, 1927.

Suborder Arthrotardigrada Marcus, 1927.

Family Stygarctidae Schulz, 1951 (emended by Hansen and Kristensen, 2006).

Subfamily Stygarctinae Schulz, 1951 (emended by Grimaldi de Zio et al., 1998).

\section{Genus Prostygarctus gen. nov.}

\section{Diagnosis}

Stygarctinae with dorsal cuticle strongly sculptured, forming five dorsal plates (one head plate; three body plates and one caudal plate). Intersegmental dorsal plates and ventral plates present. Head plate divided into five lobes; the frontal lobe subdivided into four smaller lobes. Three body plates, each with two pairs of lateral processes; the posterior-most lateral processes tapering as flexible spines. Terminal edge of segmental and intersegmental plates with paired dorsal spines directed backwards. A ventral spine is present at the level of the third pair of legs. Caudal plate with a very long medial spine and two lateral furca-like processes. Cirrus $E$ with ball and double-socket articulation. Complete set of cephalic cirri and two pairs of pedunculated elongated clavae: erect primary clavae and laterally bent secondary clavae juxtaposed to the frontal lobe of the head. Digitate legs with simple claws. Sense organs on legs IV as bulb-shaped papillae.

\section{Etymology}

The name of the genus, Pro+stygarctus, alludes to the primitive morphological appearance. It is composed by the Latin prefix pro-, meaning anterior, primitive, and the name of the genus Stygarctus Schulz, 1951, the first described armoured marine arthrotardigrade.

\section{Type species Prostygarctus aculeatus sp. nov.}

\section{Diagnosis}

Same as for genus.

\section{Etymology}

From the Latin aculeus=spine; aculeatus $=$ having spines.

\section{Type material}

The holotype, female (slide C-V38), and four paratypes, two females (slide -V39 and C-V41) and two specimens of unidentified sex (slide C-V40 and C-V42, the squeezed preparation), deposited in the Department of Biology, Faculty of Sciences, University of Porto, Portugal.

\section{Type locality}

Ofir beach (41³1'02.71'N; 0847'14.79’W), Esposende, North Portugal. Specimens possessing the same type of caudal apparatus have also been collected at Mareta beach, Sagres, South Portugal, at the high water mark in sediment samples below $1 \mathrm{~m}$ depth (Jørgensen and Møbjerg, personal communication).

\section{Description of the holotype}

Female with a body length, including the long terminal caudal spine, $171 \mu \mathrm{m}$ long (132 $\mu \mathrm{m}$ excluding) and maximum width $c .44 \mu \mathrm{m}$ at the head (Fig. 1a). Dorsal cuticle strongly sculptured (Figs. 1b and 2a) with a thin honeycomb pattern (diameter of the pores: about $0.8 \mu \mathrm{m}$ ) whereas the ventral cuticle is smooth (Fig. 1c). Plate pattern is typical of stygarctids with head plate, three body plates and caudal plate. Intersegmental single accessory plates are present. Barely distinguishable, very short and thin cuticular sheets are present in the lateral edge of the head and body plates (Fig. 2b). The head plate, almost semicircular, exhibits a high level of differentiation and is grooved into five lobes: one frontal; two medio-lateral, and two lateral (Figs. 1a and 2b). The frontal lobe is clearly subdivided into four smaller lobes by three narrow incisions. Furthermore, a subdivision of the frontal lobe into a dorsal and ventral portion is recognisable, and a large dorsal gibbosity is evident on top of the head plate (Fig. 2a). The frontal lobe bears the medial dorsal cirrus, inserted on a basal cone, and the internal dorsal cirri. Each medio-lateral lobe is separated from the frontal lobe by a deep incision, and bears both the external ventral cirri and the double walled secondary clavae. The secondary clava is elongated and bent laterally by a short peduncle, its distal extremity reaching the base of the mouth cone (Fig. 2c). The club-shaped primary clavae, with an internal van der Land's body at the base, and the lateral cirri $A$ are inserted on a short, conical, protruding pedestal, which is located in the deep indentation present between the medio-lateral and lateral lobes. All the cirri typically arise from short cirrophores with scapus and long flagellum. Eyes not observed. The sub-terminal mouth cone precedes a strongly sclerotised $\mathrm{w}$-shaped sub-cephalic ventral plate. The sub-spherical pharyngeal bulb with three placoids (visible in two paratypes) is situated at the level of the first pair of legs. Other details of the buccal apparatus were not distinguishable. 
Two pairs of lateral processes extend laterally from the body plates: the anterior-most is very short and directed sideward; the posterior-most, tapering in a caudal spike that covers almost the entire plate margin (Fig. 1a).

Caudal plate, long and conical (about $35 \mu \mathrm{m}$ long and $23 \mu \mathrm{m}$ width) extends laterally with two pairs of spiky lateral processes. Cirri $E$, placed laterally on the caudal plate, have a ball and double-socket articulation (only barely distinguishable in one paratype). A very peculiar caudal apparatus (Fig. 1a) extends the caudal plate posteriorly. It consists of a very long medial spine (c. $40 \mu \mathrm{m}$ long) with two lateral, furca-like spiky processes (c. $16 \mu \mathrm{m}$ long each).
The body plates and the caudal plate are intercalated by three single intersegmental accessory plates. On the posterior edge of the body plates 1-3 and intersegmental plates I and II, sharp, backward projecting pairs of spines are present (Fig. 1b). These projections increase in length posteriorly from barely visible on both body plate 1 and intersegmental plate I, c. 2 and $5 \mu \mathrm{m}$ long respectively on body plate 2 and intersegmental plate II, to $21 \mu \mathrm{m}$ long acute spine on body plate 3 . Intersegmental plate III has a smooth posterior edge.

Smooth ventral plates are recognisable in addition to the subcephalic plate, although these are difficult to identify and number. On the ventral plate anterior to the third
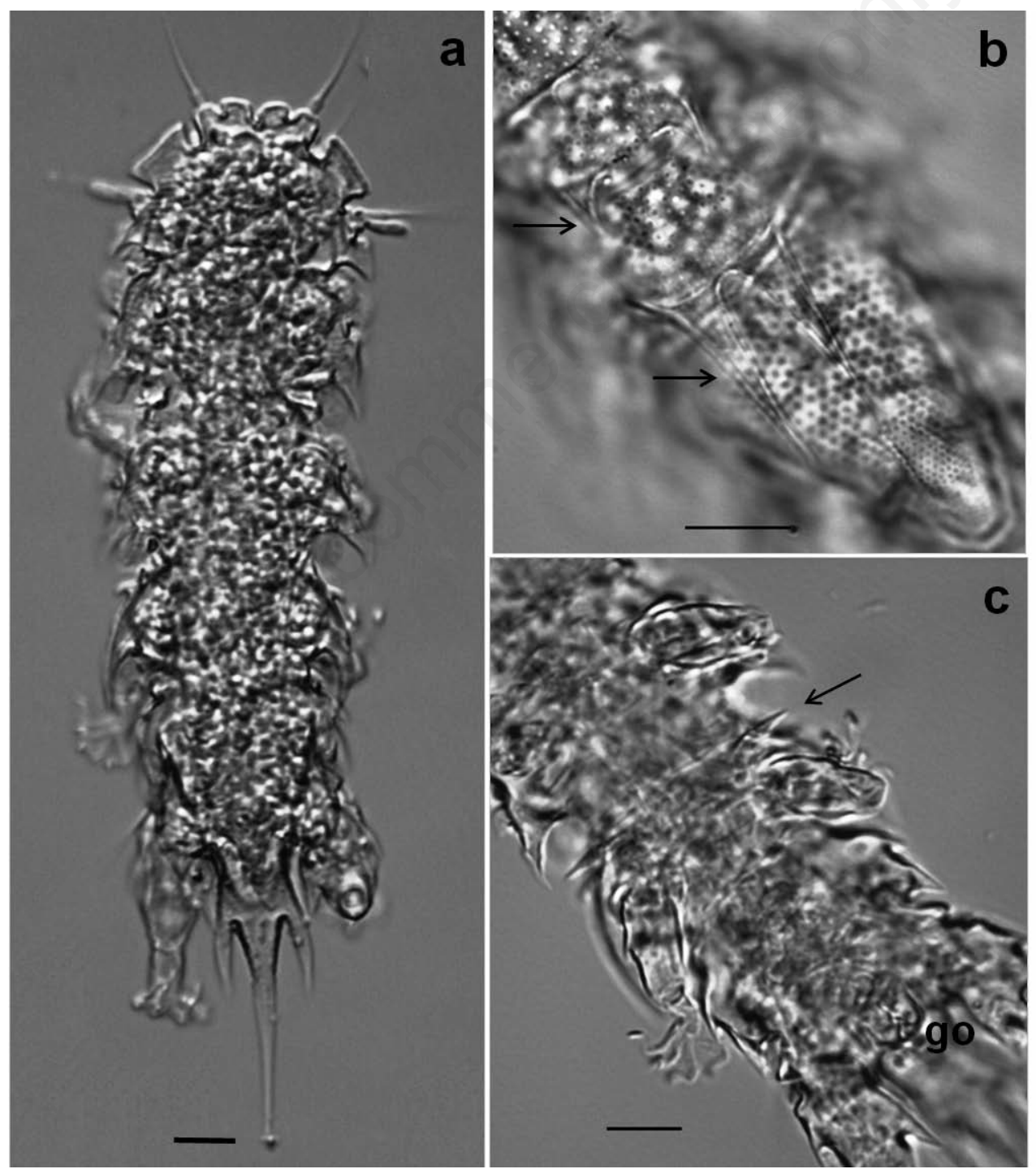

Fig. 1. Differential interference contrast images of the holotype of Prostygarctus aculeatus gen. nov., sp. nov. (scale bars=10 $\mu \mathrm{m})$ : a) habitus; b) dorsal view showing the cuticular sculpture and paired spines at terminal edge of the plates (arrows); c) ventral view where the gonopore (go) and the spines (arrow) are visible. 
pair of legs, there is a pair of very peculiar, erect, sharp spines (Fig. 1c).

Legs are long and telescopic, consisting of coxa, femur, tibia and tarsus ending in four digits with simple claws. The coxa and femur of the legs, especially those of the hind legs, are armed with several sharp lateral spines. The presence of digits is a character that needs to be carefully observed. If not, digits are easily confused with long, bent claws. The digits are flexible, with several wrinkles (Fig. 3a), ending in well developed hook-shaped claws (Fig. 3b). Accessory points are absent on both internal and external claws of all leg pairs (Fig. 3b). A bulb shaped papilla is present on the fourth pair of legs (not visible in the holotype, but confirmed in one paratype). Sense organs on the first, second and third pair of legs absent.

The circular rosette-like gonopore (Fig. 1c) lies above a papilla adjacent to the anus (both structures are visible almost at the same position but using different focus positions). In one paratype, two genital ducts with associate cuticular bars and ovoid seminal receptacles are poorly visible in an antero-lateral position to the gonopore. The anus is covered by two lateral and a small caudal platelets.

The paratypes are similar to the holotype in both qualitative and metric characters. Neither males nor larval stages were found. The measurements of some structures of the studied specimens are given in Tab. 1 .

\section{DISCUSSION}

Since the establishment of the family Stygarctidae, three other monospecific armoured arthrotardigrade families have been described: Renaudarctidae, with Renaudarctus psammocryptus Kristensen and Higgins, 1984; Neostygarctidae, with Neostygarctus acanthophorus Grimaldi de Zio, D’Addabbo Gallo, and Morone De Lucia, 1987; and Neoarctidae with Neoarctus primigenius Grimaldi de Zio, D'Addabbo Gallo, and Morone De Lucia, 1992. The neoarctids, with the cephalic sense organs distributed on both the cephalic and scapular plate, three pairs of clavae, and very different plates (i.e. numbers and thickness), belong to a very different phyletic line (Hansen et al., 2012). However, the associations of the remaining families are still problematic. Hypothesizing phylogenetic relationships among these families, Kristensen and Higgins (1984a) suggest that Neostygarctidae should be merged with Renaudarctidae. Grimaldi de Zio et al. $(1987,1990,1992)$ opposed this view (based mainly on the presence/absence of digitate legs and eyes, shape of primary clavae, cirrophorus structure, and morphology
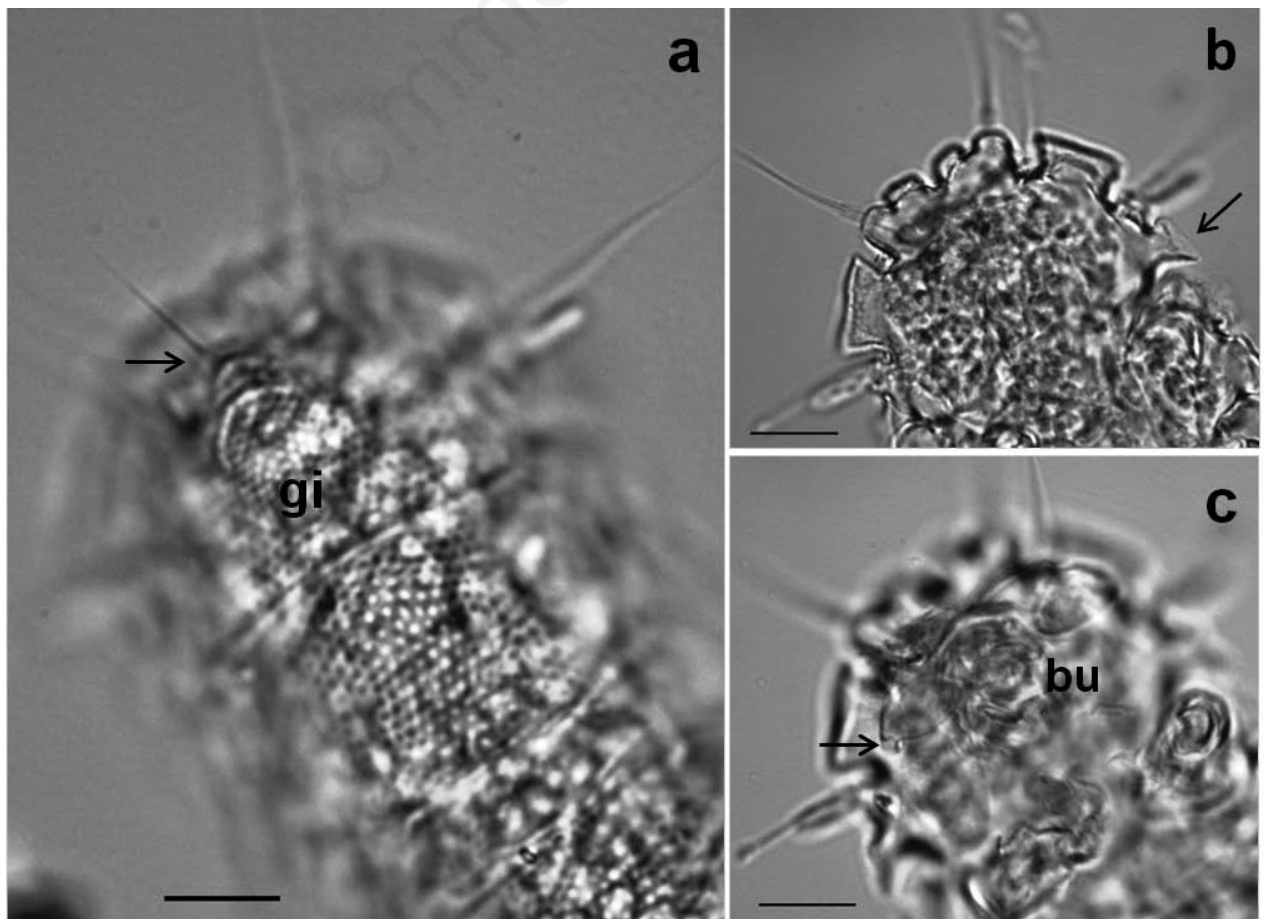

Fig. 2. Differential interference contrast images of the holotype of Prostygarctus aculeatus gen. nov., sp. nov. (scale bars=10 $\mu \mathrm{m})$ : head. a) Detail of the head plate showing the dorsal gibbosity (gi) and the medial cirrus (arrow); b) close up of the head, ventral view, showing the grooved frontal lobe, internal cephalic cirri and cuticular sheets (arrow) in the lateral edge of the head plate; c) close up of the head at a different focus position; the pedunculated secondary clavae (arrow) and the buccal cone (bu) are visible. 

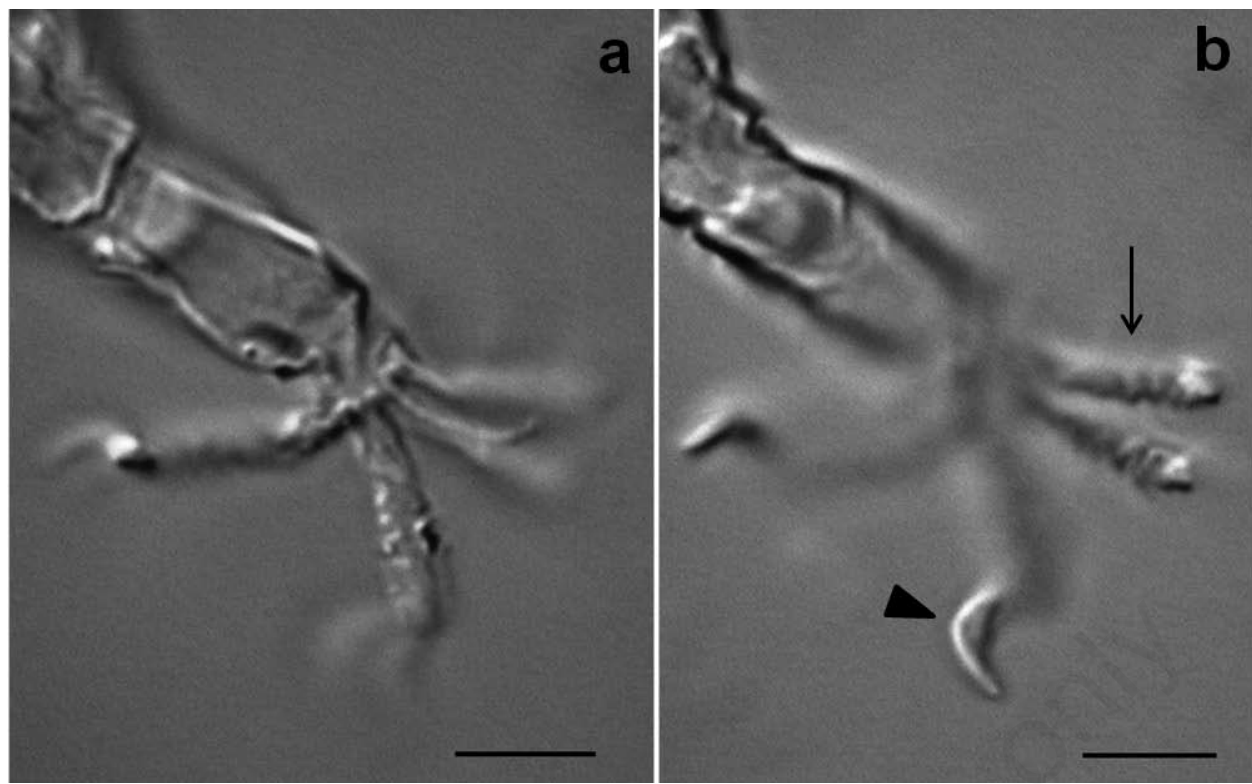

Fig. 3. Prostygarctus aculeatus gen. nov., sp. nov., close up of leg IV of a paratype at different focus positions. a) Detail of the tarsus showing the insertion of digits; b) detail of digits showing wrinkles (arrow) and simple claws (arrowhead). Scale bars $=5 \mu \mathrm{m}$.

Tab. 1. Measurements in $\mu \mathrm{m}$ of some structures of the examined specimens of Prostygarctus aculeatus gen. nov., sp. nov.

\begin{tabular}{|c|c|c|c|c|}
\hline & $\begin{array}{l}\text { Holotype } \\
\text { C-V38 }\end{array}$ & $\begin{array}{l}\text { Paratype } \\
\text { C-V41 }\end{array}$ & $\begin{array}{l}\text { Paratype } \\
\text { C-V39 }\end{array}$ & $\begin{array}{c}\text { Paratype } \\
\text { C-V40 }\end{array}$ \\
\hline Sex & Female & Female & Female & n.a. \\
\hline Body length & 171 & 163 & 177 & 178 \\
\hline Body width between legs III -IV & 41 & n.a. & 42 & n.a. \\
\hline Head plate length & 26 & 25 & 27 & 27 \\
\hline Head plate width & 44 & n.a. & 45 & n.a. \\
\hline Width of body plate 1 & 42 & 37 & 41 & n.a. \\
\hline Median cirrus & 13 & n.a. & n.a. & 12 \\
\hline Internal cephalic cirrus & 19 & n.a. & 22 & n.a. \\
\hline External cephalic cirrus & 13 & n.a. & 18 & 15 \\
\hline Lateral cirrus $A$ & 18 & n.a. & 18 & 20 \\
\hline Primary clava & 7 & n.a. & 7 & 8 \\
\hline Secondary clava & 10 & n.a. & 10 & n.a. \\
\hline Cirrus $E$ & 15 & n.a. & 13 & n.a. \\
\hline Medial caudal spike & 39 & 37 & 37 & n.a. \\
\hline Laterocaudal spike & 16 & 15 & 15 & n.a. \\
\hline Lateral spike, body plate 1 & 8 & n.a. & 8 & n.a. \\
\hline Lateral spike, body plate 2 & 8 & n.a. & 8 & 8 \\
\hline Lateral spike, body plate 3 & 14 & n.a. & 14 & 13 \\
\hline Dorsal spine, body plate 2 & 2 & 3 & 2 & 3 \\
\hline Dorsal spine, intersegmental plate II & 5 & 5 & 5 & 6 \\
\hline Dorsal spine, body plate 3 & 21 & 23 & 22 & 23 \\
\hline Ventral spike & 12 & 10 & 10 & 12 \\
\hline Pharyngeal bulb (length×width) & $10 \times 11$ & n.a. & $11 \times 12$ & $12 \times 12$ \\
\hline Placoid length & n.a. & n.a. & 5 & 5 \\
\hline Cephalic gibbosity (diameter) & 10 & 10 & 11 & 11 \\
\hline Papilla $4^{\text {th }}$ leg & n.a. & n.a. & n.a. & 6 \\
\hline Digit length, legs II-III & 5 & n.a. & 5 & n.a. \\
\hline Claw length, legs II-III & 5 & n.a. & 5 & n.a. \\
\hline Digit length, leg IV & 5 & n.a. & n.a. & 5 \\
\hline Claw length, leg IV & 6 & n.a. & n.a. & 6 \\
\hline
\end{tabular}

n.a., not available. 
of the pharyngeal apparatus), and supported the hypothesis that armoured arthrotardigrades should be split into the aforementioned families. Recently, Hansen et al. (2012), examined not only the traditional characters (systems of plates, claws and sense organs morphology), but also introduced additional characters (the seminal receptacles) to infer a new phylogenetic arrangement of the stygarctids. In the proposal, Hansen et al. (2012) removed the family Neostygarctidae leaving only two families: Renaudarctidae (emended, after the description of a second species, Renaudarctus fossorius Hansen, Kristensen and Jørgensen, 2012) and Stygarctidae, which includes two subfamilies (Megastygarctidinae Bello and De Zio Grimaldi, 1998, emended by Hansen and Kristensen, 2006, with the single genus Megastygarctides McKirdy, Schmidt and McGynty-Bayly, 1976, and Stygarctinae Schulz, 1951). In the expanded subfamily Stygarctinae, Hansen et al. (2012) have ascribed six genera: Stygarctus Schulz, 1951 (emended by Pollock, 1989), Parastygarctus Renaud-Debyser, 1965 (emended by Hansen et al., 2012), Pseudostygarctus McKirdy, Schmidt and McGyntyBayly, 1976 (emended by Hansen et al., 2012), the reinstated Mesostygarctus Renaud-Mornant, 1979 (emended by Hansen et al., 2012, from the previous assignment to Pseudostygarctus by D'Addabbo Gallo et al., 2001), Neostygarctus Grimaldi de Zio, D'Addabbo Gallo, and Morone De Lucia, 1987, and the new monospecific genus Faroestygarctus (with F. dezioae Hansen, Kristensen and Jørgensen, 2012). Nevertheless, according to Hansen et al. (2012) much uncertainty still persists regarding the phylogenetic relationships among the Stygarctinae genera due to the high number of hypothesised convergent morphological characters.

Despite the presence of digits ending in claws, we have assigned Prostygarctus aculeatus gen. nov., sp. nov. to the family Stygarctidae distinguishing it from Renaudarctidae, and the Renaudarctus species, based on the morphology of the exoskeleton, namely the presence of a deeply grooved cephalic plate, dorso-ventral flattening of the general body outline, highly telescopic legs and elongate primary clavae. With the division of the head into five lobes, all legs with the same number of claws and two lateral acute projections on all body plates, the new species seems to have more affinities with the Stygarctinae. The peculiar caudal apparatus located on the terminal edge of the dorsal plates, which consists of a very long medial spine with two lateral furca-like spiky processes, and the presence of paired, backward directed dorsal spines, differentiate Prostygarctus aculeatus gen. nov., sp. nov. from all described Stygarctinae species. Furthermore, the head plate frontal lobe is subdivided into four smaller lobes, and a pair of ventral spines is present anterior to the third pair of legs.

Within this subfamily (Stygarctinae), Neostygarctus is also characterised by having claws inserted on legs via digits. However, in the new species, the digits are wrinkled, the claws are simple, and the level of complication of the exoskeleton with its dorsal plates deeply grooved and strongly sculptured is much higher. In addition to the presence of digits with simple claws in the new species and differences in the aforementioned attributes of the exoskeleton, Prostygarctus aculeatus gen. nov., sp. nov. can also be distinguished from Neostygarctus, Parastygarctus, Pseudostygarctus, Mesostygarctus and Faroestygarctus species by different shaped sense organs. More specifically, the elongate and laterally bent secondary clavae in the new genus is not erect (as in Parastygarctus), globular (as in Neostygarctus), nor semiglobular (as in Pseudostygarctus, Mesostygarctus and Faroestygarctus. Pseudostygarctus rugosus D'Addabbo Gallo, Grimaldi de Zio and Sandulli, 2001 with kidney-shaped secondary clavae is the exception within this genus). On the other hand, while the secondary clavae of Prostygarctus aculeatus gen. nov., sp. nov. are similar to Stygarctus species, the new genus has body plates laterally extending into two acute processes, which differ from the funnel-shaped lateral expansions of the latter. Therefore, we feel the establishment of the new genus Prostygarctus is justified.

\section{CONCLUSIONS}

The discovery of our new species, which reveals intermediate characteristics among stygarctids, brings new data to the current discussion about the phylogeny and taxonomic arrangement of the armoured arthrotardigrades.

\section{ACKNOWLEDGMENTS}

We are very grateful to our colleague Aurélia Saraiva, University of Porto, for offering access to the DIC microscope. We also want to thank Sandra McInnes who kindly improved our English, and the anonymous referees for their valuable critical remarks and comments. This research was financially supported by Polis Litoral Norte, S.A. through the project Estudo de caracterização da actividade pesqueira costeira e dos seus impactes nos recursos e nas comunidades marinhas do Litoral Norte and also by the Fundação para a Ciência e Tecnologia, Portugal (Eco-Ethology Research Unit- Pest-OE/MAR/UI0331/2011). During this study, M. Rubal (SFRH/BDP/81567/2011) and P. Veiga (SFRH/BPD/81582/2011) were supported by a postdoctoral grant awarded by Fundação para a Ciência e Tecnologia.

\section{REFERENCES}

Centena P, Fontoura P, Ribeiro C, 2011. First records of marine tardigrades in the Portuguese Coast: 375 . Proc. $4^{\text {th }}$ Meet. Young Researchers of U. Porto. University of Porto ed. D’Addabbo Gallo M, Grimaldi de Zio S, Sandulli R, 2001. Het- 
erotardigrada of two submarine caves in S. Domino Island (Tremiti Islands) in the Mediterranean Sea with the description of two new species of Stygarctidae. Zool. Anz. 240:361369.

Grimaldi de Zio S, D’Addabbo Gallo M, Morone De Lucia RM, 1987. Adaptive radiation and phylogenesis in marine Tardigrada and the establishment of Neostygarctidae, a new family of Heterotardigrada. B. Zool. 54:27-33.

Grimaldi de Zio S, D’Addabbo Gallo M, Morone De Lucia RM, 1992. Neoarctus primigenius n. g., n. sp., a new Stygarctidae of the Tyrrhenian Sea (Tardigrada, Arthrotardigrada). B. Zool. 59:309-313.

Grimaldi de Zio S, D’Addabbo Gallo M, Morone De Lucia RM, 1998. A new Stygarctidae from South Tyrrhenian Sea (Tardigrada, Heterotardigrada). Cah. Biol. Mar. 39:85-91.

Grimaldi de Zio S, D’Addabbo Gallo M, Morone De Lucia RM, Troccoli A, 1990. New description of Neostygarctus acanthophorus (Tardigrada, Arthrotardigrada). Cah. Biol. Mar. 31:409-416.

Hansen JG, Kristensen RM, 2006. The "hyena female" of tardigrades and descriptions of two new species of Megastygarctides (Arthrotardigrada: Stygarctidae) from Saudi Arabia. Hydrobiologia 558:81-101.

Hansen JG, Kristensen RM, Jørgensen A, 2012. The armoured marine tardigrades (Arthrotardigrada, Tardigrada). Sci. Dan. B 2:1-91.

Kristensen RM, Higgins RP, 1984a. A new family of Arthrotardigrada (Tardigrada: Heterotardigrada) from the Atlantic Coast of Florida, U.S.A. T. Am. Microsc. Soc. 103:295-311.

Kristensen RM, Higgins RP, 1984b. Revision of Styraconyx (Tardigrada: Halechiniscidae), with description of two new species from Disko Bay, West Greenland. Smithson. Contrib. Zool. 391:1-40.

Kristensen RM, Renaud-Mornant J, 1983. [Existence d'arthrotardigrades semi-benthiques de genres nouveaux de la sousfamille des Styraconyxinae subfam. nov]. [Article in French]. Cah. Biol. Mar. 24:337-353.

Marcus E, 1936. Tardigrada. Das Tierreichs 66:1-340.

Pollock LW, 1989. Marine interstitial Heterotardigrada from the Pacific Coast of the United States, including a description of Batillipes tridentatus n. sp. T. Am. Microsc. Soc. 108:169-189.

Ramazzotti G, Maucci W, 1983. [Il Phylum Tardigrada. Terza edizione riveduta e aggiornata]. [Article in Italian]. Mem. Ist. Ital. Idrobiol. 41:1-1012.

Thulin G, 1942. [Ein neuer mariner Tardigrad. Meddel]. [Article in German]. Göteborgs Mus. Zool. 99:1-10. 